\title{
Phospholipid Ester-linked Fatty Acid Biomarkers of Acetate-oxidizing Sulphate-reducers and Other Sulphide-forming Bacteria
}

\author{
By NICHOLAS J. E. DOWLING, ${ }^{1 *}$ FRIEDRICH WIDDEL ${ }^{2}$ \\ AND DAVID C. WHITE ${ }^{1}$ \\ ${ }^{1}$ Department of Biological Science, Florida State University, Tallahassee, \\ Florida 32306-3043, USA \\ ${ }^{2}$ Fakultät für Biologie, Universität Konstanz, Postfach 5560 D-7750, Konstanz, FRG
}

(Received 11 September 1985; revised 28 February 1986)

\begin{abstract}
The phospholipid ester-linked fatty acids were examined in four Desulfobacter strains (2ac9, $\mathrm{AcBa}, 3 \mathrm{ac10}$ and 4ac11), a Desulfobacter-like 'fat vibrio' (AcKo) and Desulfotomaculum acetoxidans (5575), which are all sulphate-reducing bacteria that oxidize acetate. A thermophilic sulphate reducer, Desulfovibrio thermophilus, and two sulphur-reducing bacteria, Desulfuromonas acetoxidans (11070) and a Campylobacter-like spirillum (5175), were also studied. The Desulfobacter spp. were characterized by significant quantities of 10-methylhexadecanoic acid. Other 10-methyl fatty acids were also detected in Desulfobacter spp. No 10-methyl fatty acids were detected in the other organisms examined, supporting the use of 10-methylhexadecanoic acid as a biomarker for Desulfobacter. High levels of cyclopropyl fatty acids, including two isomers of both methylenehexadecanoic (cy17:0) and methyleneheptadecanoic (cy18:0) acids, were also characteristic of Desulfobacter spp. The influence of the volatile fatty acids (VFA) propionate, isobutyrate, isovalerate and 2-methylbutyrate on the lipid fatty acid distribution was studied with two Desulfobacter strains (2ac9, $\mathrm{AcBa}$ ) and Desulfotomaculum acetoxidans. Although these sulphate reducers cannot oxidize the VFA, their presence in the acetate growth medium caused a shift in the fatty acid distribution in favour of odd-numbered and branched chains by apparent direct incorporation into the fatty acids as chain initiators. The Desulfobacter strains were distinguished from other sulphide-forming bacteria by the percentage of unsaturated and the percentage of branched fatty acids.
\end{abstract}

\section{INTRODUCTION}

Sulphate-reducing bacteria perform the terminal process in anaerobic degradation of organic matter in aquatic environments. These bacteria oxidize low- $M_{\mathrm{r}}$ compounds formed by fermentative bacteria and use sulphate as terminal acceptor, the sulphate being reduced to sulphide. In sulphate-rich habitats such as marine sediments, more than half of the incoming detritus may be mineralized via sulphate reduction (Jørgensen, 1977, 1982; Sansone \& Martens, 1982). If sulphate is absent or limiting, as in most freshwater sediments, the terminal degradation step is taken over by methanogenic bacteria and their syntrophic partners (Banat \& Nedwell, 1983; Winfrey \& Zeikus, 1977; Stieb \& Schink, 1985). Molecular hydrogen and acetate are the two key intermediates via which dead biomass (necromass) is channelled into either sulphate reduction or methanogenesis (Loveley et al., 1982; Sørensen et al., 1981; Winfrey \& Zeikus, 1977). Desulfovibrio spp. and Desulfobulbus spp. are potentially hydrogen-scavenging sulphate reducers in nature (Brandis \& Thauer, 1981; Kristjansson et al., 1982; Taylor \& Parkes, 1985). In the laboratory, Desulfovibrio spp. are usually cultivated on lactate (Postgate, 1984), which is probably not a major anaerobic intermediate under natural conditions. Acetate is

Abbreviations: FAME, fatty acid methyl esters; VFA, volatile fatty acids. 
oxidized by various sulphate-reducing bacteria (Pfennig et al., 1981); however, only a few species of these, namely Desulfobacter spp. and Desulfotomaculum acetoxidans, really grow well on acetate (Widdel \& Pfennig, 1977, 1981a,b) and may, therefore, be significant acetate oxidizers under natural conditions. Desulfobacter postgatei exhibits a high affinity for acetate (Schönheit et al., 1982; Ingvorsen et al., 1984). Desulfobacter spp. usually do not utilize hydrogen, whereas Desulfovibrio spp. and Desulfobulbus spp. cannot oxidize acetate. Thus, there are apparently functionally distinctive groups of sulphate-reducing bacteria (Banat et al., 1981).

If elemental sulphur is present, this may be used as terminal acceptor by sulphur-reducing bacteria (Jørgensen, 1982; Smith \& Klug, 1981). Mesophilic, eubacterial sulphur reducers that oxidize hydrogen are represented by Campylobacter-like spirilla (Wolfe \& Pfennig, 1977; Pfennig \& Biebl, 1981), and sulphur reducers that oxidize acetate by Desulfuromonas spp. (Pfennig \& Biebl, 1976, 1981).

Quantitative assay of bacterial biomass and community structure in marine or other sediments requires methods that avoid the problems associated with quantitative recovery of bacteria from surfaces and selective culturing procedures (White, 1983). Recent work has shown that fatty acid analysis may be a powerful tool in the interpretation of microbial community structure (Bobbie \& White, 1980) as well as in microbial taxonomy (Minnikin et al., 1978). Few articles detail the lipids of the sulphide-forming eubacteria, most being concerned with the lactate- or hydrogen-utilizing sulphate-reducing bacteria (i.e. Desulfovibrio spp. and Desulfotomaculum spp.), which commonly exhibit branched monoenoic 17-carbon fatty acids as major components (Makula \& Finnerty, 1974, 1975; Ueki \& Suto, 1979; Edlund et al., 1985; Boon et al., 1977). Taylor \& Parkes (1983) investigated the cellular fatty acids of a Desulfobacter sp. (strain 3ac10) utilizing acetate, a Desulfobulbus sp. (strain 3pr10) able to utilize propionate, hydrogen or lactate, and a Desulfovibrio desulfuricans strain. The Desulfobacter strain exhibited high proportions of 10-methylhexadecanoic acid (10Me16:0), which had previously been observed in anoxic marine sediments (Volkman et al., 1980; Parkes \& Taylor, 1983; Perry et al., 1979). Because of its absence in Desulfobulbus and Desulfovibrio, 10Me16:0 was proposed as a biomarker for Desulfobacter spp. in these environments. Hitherto, saturated 10-methyl fatty acids have only been observed in actinomycetes and related taxa (Kroppenstedt \& Kutzner, 1978).

In this study, we examined other Desulfobacter strains for 10Me16:0 to determine if it could be of use as a more general biomarker for that genus. The hydrogen- or lactate-utilizing thermophilic Desulfovibrio thermophilus (Rozanova \& Khudyakova, 1974) was included in the study in order to compare its phospholipid fatty acids with those of mesophilic Desulfovibrio spp. Two representatives of sulphur reducers were also examined: the hydrogen-oxidizing Campylobacter-like spirillum 5175 (Wolfe \& Pfennig, 1977) and the acetate-oxidizing Desulfuromonas acetoxidans (Pfennig \& Biebl, 1976). The effects of supplementing the culture medium with volatile fatty acids (not required for growth) on the phospholipid fatty acids of three acetate-utilizing strains were also investigated.

\section{METHODS}

Bacterial strains and culture methods. The origins and nutritional capacities of all the strains examined are listed in Table 1.

The 'fat vibrio' strain AcKo is a new isolate from an ammonia-limited freshwater enrichment on acetate. Strain AcKo resembles Desulfobacter postgatei in that it uses only acetate as electron donor and its growth is stimulated in brackish media ; however, AcKo has motile fat vibrio-shaped cells, whereas Desulfobacter cells are oval to rodshaped and scarcely motile in pure cultures.

The strains were grown in anaerobic 2 litre batch cultures in bicarbonate-buffered media reduced with sulphide and dithionite as described by Pfennig et al. (1981). The rubber-sealed culture bottles had a small gas phase of $10-20 \%(\mathrm{v} / \mathrm{v}) \mathrm{CO}_{2}$ in $\mathrm{N}_{2}$. The media were supplemented with vitamins, but contained no yeast extract, chelating agents or redox indicator. For Desulfovibrio thermophilus, bicarbonate was omitted and the phosphate concentration was increased from 0.2 to $0.8 \mathrm{~g} \mathrm{KH}_{2} \mathrm{PO}_{4} \mathrm{l}^{-1}$. The strains required different concentrations of $\mathrm{NaCl}$ and $\mathrm{MgCl}_{2} .6 \mathrm{H}_{2} \mathrm{O}$ in their media for optimal growth; the respective concentrations were as follows $\left(\mathrm{g}^{-1}\right): 1.0$ and 0.5 for Desulfotomaculum acetoxidans, Desulfovibrio thermophilus and spirillum 5175; 7.0 and 1.2 for Desulfobacter postgatei and the fat vibrio AcKo; 20.0 and 3.0 for Desulfuromonas acetoxidans and the Desulfobacter strains AcBa, 


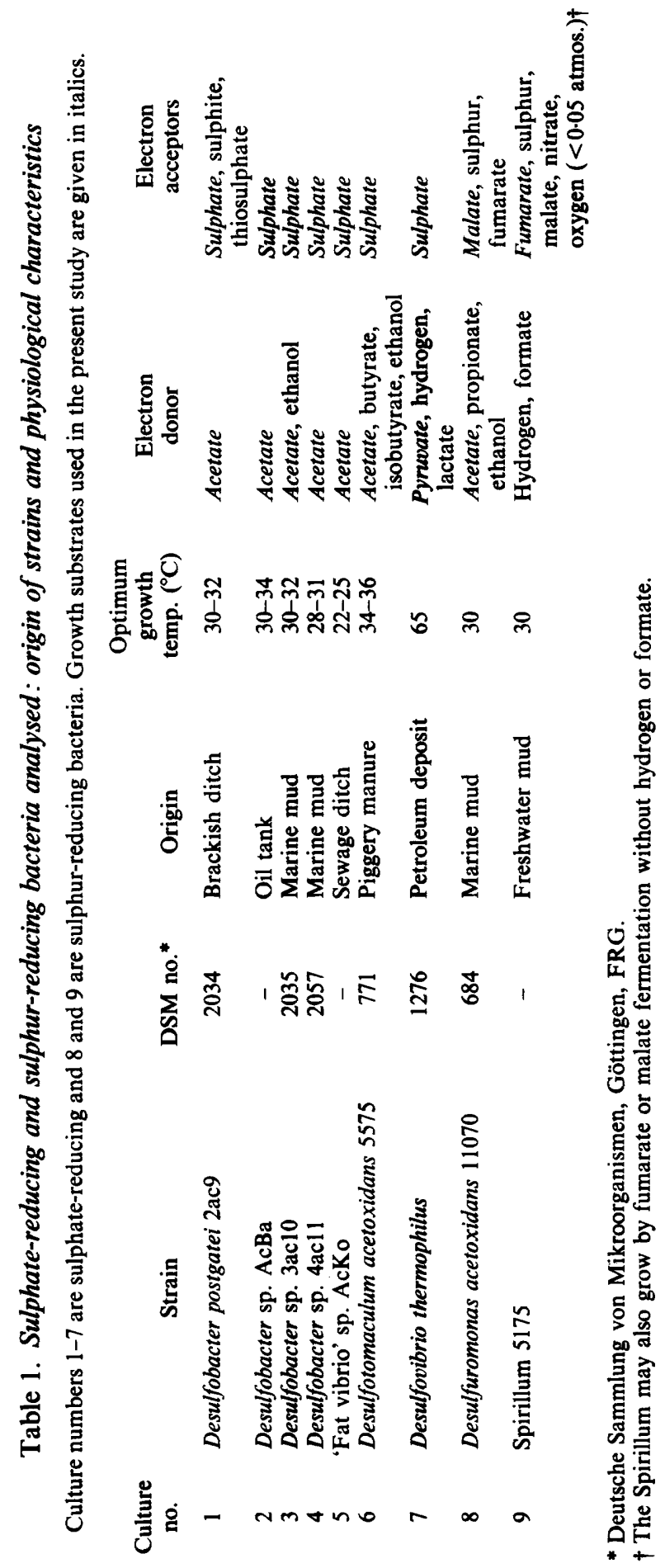


$3 \mathrm{ac} 10$ and 4acl1. Media for sulphate reducers contained $25 \mathrm{~mm}$-sulphate. Desulfovibrio thermophilus was grown on pyruvate (filter-sterilized; pore size $0.2 \mu \mathrm{m}$; final concentration $20 \mathrm{mM}$ ). In order to facilitate harvesting of the sulphur reducers, they were grown on alternative, purely organic energy sources: spirillum 5175 was cultivated on fumarate ( $40 \mathrm{mM}$, gradually added during growth), Desulfuromonas acetoxidans on acetate (10 mM) plus malate (40 mM, gradually added). Desulfobacter postgatei, Desulfobacter strain AcBa and Desulfotomaculum acetoxidans were grown in duplicate cultures on acetate, one of each pair containing, in addition, the following VFA (final concentrations in mM): propionate (2), isobutyrate (1), isovalerate (1), 2-methylbutyrate (1). All strains were grown in the dark at their respective optimum temperature (Table 1) and were briefly shaken twice a day. Cells were harvested by centrifugation at the end of exponential growth phase and lyophilized for lipid extraction.

Lipid extraction and separation. Lipids were extracted by a modified version (White et al., 1979) of the procedure of Bligh \& Dyer (1959). After recovery in chloroform, the lipids were fractionated on a silicic acid column (Gehron \& White, 1983). Unisil $\left(1 \mathrm{~g}, 100-200\right.$ mesh) silicic acid (activated at $100^{\circ} \mathrm{C}, 1 \mathrm{~h}$ ) was slurried into glass columns with chloroform. Total extractable lipid was then applied to the silicic acid in $2 \mathrm{ml}$ chloroform. Neutral lipids were eluted with $10 \mathrm{ml}$ chloroform, glycolipids with $10 \mathrm{ml}$ acetone and phospholipids with $10 \mathrm{ml}$ methanol. Phospholipid solutions were evaporated to dryness under a stream of nitrogen and stored at $-70^{\circ} \mathrm{C}$.

Methanolysis of phospholipid fatty acids. Phospholipids were dissolved in $1 \mathrm{ml}$ methanol/toluene $(1: 1, \mathrm{v} / \mathrm{v}), 1 \mathrm{ml}$ $0 \cdot 2 \mathrm{M}-\mathrm{KOH}$ was added and the samples were heated at $37^{\circ} \mathrm{C}$ for $15 \mathrm{~min}$. Sequential additions of $2 \mathrm{ml}$ hexane, $0.3 \mathrm{ml} 1 \mathrm{M}$-acetic acid and $2 \mathrm{ml}$ water were made. The biphasic mixture was vortexed, and the hexane (upper) layer, containing the fatty acid methyl esters (FAME), was removed. The partition against $2 \mathrm{ml}$ hexane was repeated. Combined hexane fractions were dried under a stream of nitrogen and stored at $-70^{\circ} \mathrm{C}$.

Thin layer chromatography (TLC). Crude FAME were loaded onto a thin layer silica gel (Whatman KG, $0.25 \mathrm{~mm}, 20 \times 20 \mathrm{~cm}$ ) plate. Standard methyl nonadecanoate was spotted onto end lanes on each plate. After development of the TLC plates in hexane/diethyl ether $(1: 1, \mathrm{v} / \mathrm{v})$ the end lanes were sprayed with $0.1 \%(\mathrm{w} / \mathrm{v})$ Rhodamine to detect the standard. Areas at $R_{F}$ values corresponding to the standards were scraped off and the FAME eluted from the silica with hexane. The solvent was dried under a stream of nitrogen and the FAME taken up in an appropriate volume of hexane for gas chromatography. Methyl nonadecanoate was added as an internal injection standard.

Saturated and unsaturated FAME were separated on TLC plates as before, but the plates were predeveloped in $20 \mathrm{~g} \mathrm{AgNO}_{3}, 60 \mathrm{ml}$ water and $120 \mathrm{ml}$ absolute ethanol in the dark. Development and recovery of saturated FAME using an external standard of methyl nonadecanoate was as described above.

Determination of fatty acid double bond position. This was done by gas chromatography-mass spectrometry (GC-MS) analysis of their Diels-Alder adducts (Kidwell \& Bleman, 1982), as modified by Nichols et al. (1985), or of dimethyl disulphide derivatives (Dunkelblum et al., 1985).

Determination of fatty acid cyclopropyl position. This procedure was modified from McCloskey \& Law (1967), and Kaneshiro \& Marr (1961). Cyclopropyl FAME (approximately $5 \mathrm{mg}$ ) were hydrogenated in the presence of $\mathrm{PtO}_{2}$ $(2 \mathrm{mg})$ and glacial acetic acid $(0.2 \mathrm{ml})$, under $275 \mathrm{kPa} \mathrm{H}$, while stirring with a glass coated magnetic stirring bar for $20 \mathrm{~h}$. The solvent was removed under nitrogen, and the FAME were analysed by GC-MS.

GC and GC-MS. Gas chromatography was done on a Varian model 3700 using a flame ionization detector and a non-polar cross-linked methyl silicone fused silica capillary column $(50 \mathrm{~m} \times 0.2 \mathrm{~mm}$ i.d., Hewlett Packard). Injector and detector temperatures were $250^{\circ} \mathrm{C}$ and $290^{\circ} \mathrm{C}$ respectively. The oven temperature was programmed from $80^{\circ} \mathrm{C}$ to $140^{\circ} \mathrm{C}$ at $20^{\circ} \mathrm{C} \mathrm{min}-1$, then at $4^{\circ} \mathrm{C} \mathrm{min}-1$ to $270^{\circ} \mathrm{C}$, and then isothermal for $10 \mathrm{~min}$. Hydrogen was used as carrier gas at $30 \mathrm{~cm} \mathrm{sec}^{-1}$ (linear velocity). Peak areas were integrated by a Hewlett Packard 3350 series programmable laboratory data system operated in an internal standard programme mode.

Initial GC-MS analysis was done on a Hewlett Packard 5995A system fitted with a direct capillary inlet (Nichols et al., 1985). Several samples were also analysed with the following GC-MS parameters: splitless injection at $100^{\circ} \mathrm{C}$; the oven programmed from $100^{\circ} \mathrm{C}$ to $300^{\circ} \mathrm{C}$ at $4{ }^{\circ} \mathrm{C} \mathrm{min}-1$; helium as the carrier gas; electron multiplier 1300-1400 V; transfer line $300^{\circ} \mathrm{C}$; source and analyser $250^{\circ} \mathrm{C}$; autotune file DFTPP normalized; optics tuned at $\mathrm{m} / \mathrm{z} 502$; MS peak threshold $=300$ triggered on total ion abundance; electron impact energy $=70 \mathrm{eV}$. Mass spectral data were processed with a Hewlett Packard RTE-6/VM data system.

Criteria for the identification of FAME. Identification of individual fatty acids relied upon GC retention time; argentation TLC separation of unsaturated and saturated FAME; derivatization of monoenoic acids for the determination of double bond positions; and the hydrogenation of cyclopropyl groups for mass spectral analysis of the resultant branched FAME. Original FAME were also examined by GC-MS. Interpretation of mass spectral data and component identification was achieved by comparison with published data (Dinh-Nguyen et al., 1961; Ryhage \& Stenhagen, 1958; Rohwedder et al., 1965; Campbell \& Naworal, 1969).

\section{RESULTS}

The phospholipid ester-linked fatty acid distributions of the Desulfobacter spp. and of all the other sulphide-forming bacteria analysed are listed in Tables 2 and 3, respectively. For ease of 
Table 2. Percentage phospholipid ester-linked fatty acids of Desulfobacter spp. grown on acetate

Cultures are numbered according to Table 1 . Fatty acids are characterized by chain length and position of substituents from the methyl $(\omega)$ end. Thus $16: 1 \omega 7 \mathrm{c}$ is $\omega 7$-cis-hexadecenoic acid. Iso and anteiso FAME are methyl-branched one and two carbons from the methyl end, respectively. Unsaturation may occur in either cis (c) or trans $(t)$ configurations. Other notation: tr, trace quantities $(<0.1 \%)$; br, multiple branching; SAT, unknown saturated fatty acid; $a$, FAME detected by double bond analysis only, and not quantified; *, positional data for double bond, methyl branch or cyclopropyl ring (cy) based on GC retention time only (insufficient sample was available for analysis). Cultures + VFA were grown with additional volatile fatty acid (final concentration $\mathrm{mm}$ ): propionate (2), isobutyrate (1), isovalerate (1), 2-methylbutyrate (1).

Culture no.

\section{FAME}

13:0

isol 4:0

anteisol 4:0

$14: 1 \omega 7$

$14: 1 \omega 5$

$14: 0$

br15:1*

iso $15: 0$

anteisol 15:0

15: $1 \omega 8$

$15: 1 \omega 6$

$15: 1 *$

$15: 0$

10Me15:0

br16: $1 \omega 6 c *$

iso 16:0

anteiso16:0

16:1 $1 \omega 9$

$16: 1 \omega 7 \mathrm{c}$

$16: 1 \omega 7 \mathrm{t}$

$16: 1 \omega 5$

cy 16:0*

16:0

iso 17: $1 \omega 7$

10Me16:0

iso 17:0

anteiso 1 7:0

$17: 1 \omega 8$

$17: 1 \omega 7$

17:1 106

cy17:0a $(\omega 7 / 8)$

cy 17:0b*

brSAT*

17:0

br18:1*

10Me17:0

$18: 1 \omega 9$

$18: 1 \omega 7 \mathrm{c}$

$18: 1 \omega 7 \mathrm{t}$

cy $18: 0 \mathrm{a}$ *

cy $18: 0 \mathrm{~b}$ *

18:0

br19:1*

10Me18:0

anteiso 19:0

cy 19:0*

Trace components

Branched FAME

Unsaturated FAME

$\mu \mathrm{mol}(\mathrm{g} \text { dry } \mathrm{wt})^{-1}$

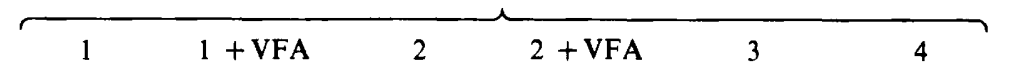

(1.

tr

$0 \cdot 3$

-
0.2
-
0.2
-
2.4
0.8
8.9
4.0

tr

$0 \cdot 1$

$0 \cdot 4$

tr

31.4

tr

$1 \cdot 6$

0.1

$-$

1.5

12.

1.4

1.2

$1 \cdot 2$
-

0.6

$2 \cdot 1$

$-$

$1 \cdot 3$

1.8

11.9

1.5

9.1

$1 \cdot 3$

$1 \cdot 3$

2.0

-

8.9
10.0

0.8

2.9

2.9
1.4

1.4
2.4

0.2

0.5

0.5
-

0.8

4.5

0.3

0.4

0.4
-

$0 \cdot 1$

0.6

$0 \cdot 1$

34.5

21.4

$77 \cdot 3$

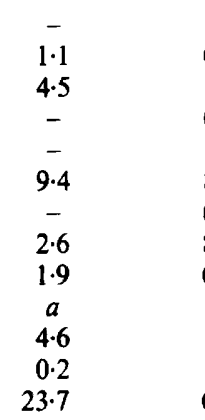

\section{tr}

$0 \cdot 2 \quad$ tr

0.3

$8 \cdot 8$

0.8

8.7

0.2

tr

$0 \cdot 1$

$$
0 \cdot 7
$$

$23 \cdot 7$

1.9

0.9

$5 \cdot 3$

$1 \cdot 8$

tr

tr

tr

$11 \cdot 3$

tr

$2 \cdot 1$

$0 \cdot 1$

0.8

a

$\operatorname{tr}$
0.4

\section{4}

$-$

$0 . \overline{2}$

0.9

5.9

$0 \cdot 2$

1.8

$-$

$6 \cdot 3$

0.3

1. 1

$0 \cdot 1$

1.4

18.6

$0 \cdot 1$

$9 \cdot 4$

$7 \cdot 4$

$0 \cdot 1$

$6 \cdot 3$

$-$

0.7

$-$

3.6
11.8

11.8

0.2

1.0

0.3

$2 \cdot 1$

tr

$-$

$-$

0.9

0.8

0.4

$-$ 
Table 3. Percentage phospholipid ester-linked fatty acids of a Desulfobacter-like 'Fat vibrio', non-Desulfobacter sulphate reducers and sulphur reducers

For definition of abbreviations see Table 2.

\begin{tabular}{|c|c|c|c|c|c|c|}
\hline \multirow[b]{2}{*}{ FAME } & \multicolumn{6}{|c|}{ Culture no. } \\
\hline & 5 & 6 & $6+$ VFA & 7 & 8 & 9 \\
\hline iso14:0 & tr & - & 0.3 & - & - & - \\
\hline $14: 1 \omega 7$ & 0.2 & - & - & - & $0 \cdot 1$ & $0 \cdot 3$ \\
\hline $14: 1 *$ & 0.1 & - & - & - & $0 \cdot 1$ & - \\
\hline $14: 0$ & $5 \cdot 5$ & $1 \cdot 3$ & 0.6 & - & $2 \cdot 1$ & $3 \cdot 1$ \\
\hline br15:1* & 0.3 & - & - & - & $\operatorname{tr}$ & - \\
\hline isol 5:0 & $3 \cdot 5$ & 0.5 & 0.9 & $0 \cdot 3$ & $4 \cdot 4$ & $\operatorname{tr}$ \\
\hline anteisol 15:0 & $\operatorname{tr}$ & - & - & $0 \cdot 2$ & 0.4 & tr \\
\hline $15: 1 \omega 8$ & - & - & $a$ & - & - & - \\
\hline $15: 1 \omega 6$ & tr & - & 0.4 & - & 0.8 & $0 \cdot 1$ \\
\hline $15: 1 \omega 5$ & - & - & $a$ & - & - & $a$ \\
\hline $15: 0$ & 0.1 & $0 \cdot 3$ & 4.5 & - & - & 1.0 \\
\hline br $16: 1 \omega 6 *$ & $\operatorname{tr}$ & - & $3 \cdot 2$ & - & - & - \\
\hline isol6:0 & 0.2 & - & 2.0 & $23 \cdot 4$ & 0.1 & - \\
\hline $16: 1 \omega 9$ & 0.8 & 5.9 & 3.5 & - & - & - \\
\hline $16: 1 \omega 7 \mathrm{c}$ & 23.9 & $24 \cdot 4$ & $13 \cdot 4$ & - & $37 \cdot 3$ & $50 \cdot 1$ \\
\hline $16: 1 \omega 7 \mathrm{t}$ & 0.4 & 0.6 & $\operatorname{tr}$ & - & 0.5 & $1 \cdot 1$ \\
\hline $16: 1 \omega 5$ & 1.6 & $4 \cdot 8$ & $2 \cdot 6$ & - & $2 \cdot 6$ & $1 \cdot 3$ \\
\hline 16:0 & 41.5 & 34.0 & $22 \cdot 2$ & $4 \cdot 1$ & $47 \cdot 3$ & 31.8 \\
\hline isol $7: 1 \omega 7$ & 1.0 & - & - & - & 0.2 & - \\
\hline isol 1:0 & 0.6 & - & - & $9 \cdot 6$ & 0.7 & - \\
\hline anteisol 17:0 & $\mathrm{tr}$ & - & - & 39.6 & - & - \\
\hline $17: 1 \omega 8$ & - & - & $5 \cdot 2$ & - & 0.4 & $\operatorname{tr}$ \\
\hline $17: 1 \omega 6$ & - & - & $13 \cdot 3$ & - & 0.6 & 0.5 \\
\hline cy17:0a $(\omega 7 / 8)$ & $18 \cdot 2$ & - & - & - & - & - \\
\hline cyl7:0b* & $1 \cdot 1$ & - & - & - & - & - \\
\hline $17: 0$ & $\operatorname{tr}$ & - & $7 \cdot 0$ & 0.8 & 0.8 & 0.2 \\
\hline iso18:0 & - & - & - & 12.9 & - & - \\
\hline $18: 1 \omega 9$ & 0.1 & 1.0 & 0.9 & - & $\operatorname{tr}$ & - \\
\hline $18: 1 \omega 7 \mathrm{c}$ & 0.5 & $24 \cdot 1$ & $17 \cdot 0$ & - & 0.8 & $9 \cdot 7$ \\
\hline $18: 1 \omega 7 \mathrm{t}$ & - & 0.4 & - & - & - & 0.2 \\
\hline $18: 1 \omega 5$ & - & $1 \cdot 4$ & 0.9 & - & $\operatorname{tr}$ & 0.1 \\
\hline $18: 0$ & tr & 1.2 & $1 \cdot 2$ & 7.7 & 0.4 & 0.2 \\
\hline isol9:0 & - & - & - & 0.3 & - & - \\
\hline anteiso19:0 & $\operatorname{tr}$ & - & 0.8 & 0.9 & 0.2 & $\operatorname{tr}$ \\
\hline cy19:0* & 0.3 & - & - & - & - & - \\
\hline Trace components & $0 \cdot 1$ & 0.1 & $0 \cdot 1$ & 0.2 & 0.2 & 0.3 \\
\hline Branched FAME & $5 \cdot 6$ & 0.5 & $7 \cdot 2$ & $87 \cdot 2$ & $6 \cdot 0$ & $\operatorname{tr}$ \\
\hline Unsaturated FAME & 28.9 & 62.6 & $60 \cdot 4$ & 0.0 & $43 \cdot 4$ & 63.4 \\
\hline$\mu \mathrm{mol}(\mathrm{g} \text { dry wt) })^{-1}$ & 81.5 & 19.8 & 9.8 & 13.8 & 61.5 & $49 \cdot 2$ \\
\hline
\end{tabular}

interpretation of major differences, the total percentages of branched and unsaturated fatty acids occurring in each strain are presented at the bottom of each table. Due to the constraints of time and materials only one batch culture of each strain and set of conditions was analysed. Previously this laboratory has shown that phospholipid fatty acid profiles of duplicate batch cultured bacteria usually have a standard deviation of less than $1 \%$ for each fatty acid (e.g. Edlund et al., 1985).

The sulphide-forming bacteria in this study are clearly distinguished by the presence or absence of 10-methyl fatty acids. Among the strains examined, 10-methyl fatty acids occur exclusively and consistently in the Desulfobacter spp. In Desulfobacter spp. grown on acetate, 10Me16:0 ranged from $24.7 \%$ in Desulfobacter sp. 3 ac10 to $9.4 \%$ in Desulfobacter sp. AcBa.

VFA were added to cultures of Desulfobacter postgatei 2ac9, Desulfobacter $\mathrm{sp}$. AcBa and Desulfotomaculum acetoxidans 5575. In these cultures, all even-numbered fatty acids were 


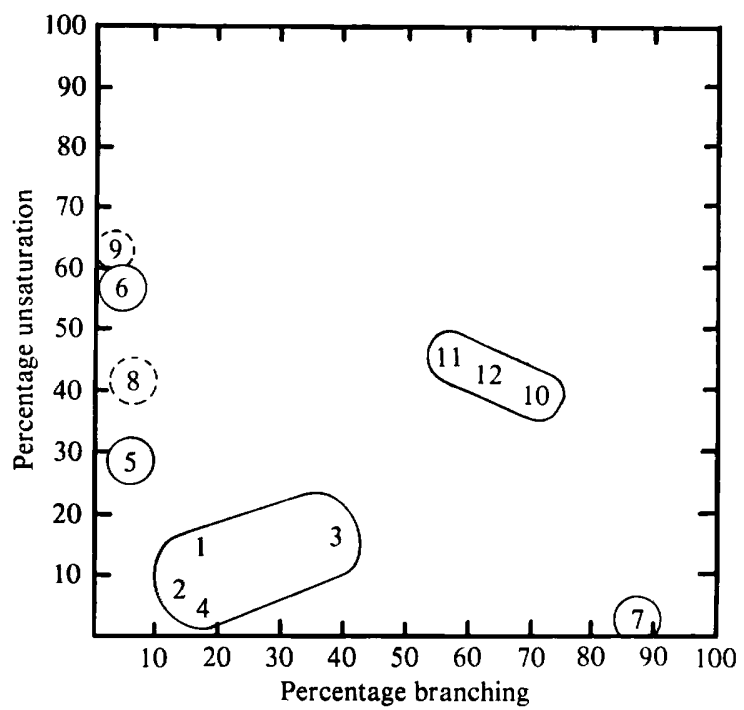

Fig. 1. Graph illustrating the distribution of the sulphidogenic bacteria based on percentage unsaturation and percentage branching of their fatty acids. Numbers refer to the culture numbers in Table 1 except for: 10, Desulfovibrio desulfuricans; 11 , Desulfovibrio vulgaris; 12 , Desulfovibrio africanus. Strains 10-12 are shown for reference; the data for them is from Edlund et al. (1985), by kind permission of the authors. Broken lines: sulphur-reducing bacteria.

present in decreased proportions. Those of strain $2 \mathrm{ac} 9$ decreased from 67 to $39 \%$ with respect to the total, those of strain AcBa from 69 to $47 \%$ and those of strain 5575 from 99 to $67 \%$. Simultaneously the branched chain fatty acids increased (2ac9, from 19 to $34 \%$; AcBa, from 12 to $27 \% ; 5575$, from 0.5 to $7 \%$ ).

All the Desulfobacter spp. grown on acetate were characterized by even-numbered fatty acid distributions ranging from $77 \%(3 \mathrm{ac} 10)$ to $59 \%(4 \mathrm{ac} 11)$. 10-Methyl fatty acids other than 10Me16:0 were detected, including 10Me15:0 (2ac9 + VFA), 10Me17:0 (2ac9 \pm VFA; AcBa +VFA; 3ac10 -VFA; 4ac11 -VFA) and 10Me18:0 (3ac10 - VFA). Components in insufficient quantity for structural confirmation by GC-MS (2ac9 - VFA; AcBa + VFA; $3 \mathrm{ac10}$ ) had identical retention times to $10 \mathrm{Me15:0}$; these components are not listed in Table 2.

Cyclopropyl fatty acids are also characteristic of Desulfobacter spp. The major component was $\omega 7 / \omega 8$ methylenehexadecanoic acid (cy17:0a), which ranged from $30 \%$ in 4 ac1 1 to $7 \%$ in $3 a c 10$ when the bacteria were grown on acetate without the VFA. The position of the cyclopropyl group in a second methylenehexadecanoic acid (cy17:0b) was not identified; this fatty acid ranged from $0 \%$ in AcBa to $3 \%$ in $4 \mathrm{acl} 1$ and $2 \mathrm{ac} 9$ under the same conditions. Desulfobacter spp. 2ac9 and AcBa showed a decrease in proportion of cyclopropyl fatty acids when VFA were included in the media (2ac9, from 28 to $18 \%$; AcBa, from 27 to $13 \%$ ). Other cyclopropyl FAME were also detected including cy 16:0 (2ac9 + VFA) and two cyclopropyl 18:0 FAME designated cy $18: 0 \mathrm{a}$ and cy $18: 0 \mathrm{~b}$.

The 'fat vibrio' strain AcKo grown on acetate had $75 \%$ even-numbered and $94 \%$ straightchain fatty acids, with high levels of cy17:0 (cy17:0a, 18\%; cy17:0b, 1\%) similar to the Desulfobacter spp.; however, no 10-methyl FAME could be detected.

Desulfotomaculum acetoxidans 5575 grown on acetate gave a distribution of $99 \%$ evennumbered and $99 \%$ straight-chain fatty acids. Incorporation of VFA into the medium decreased the proportions of even-numbered and straight-chain fatty acids to 68 and $93 \%$, respectively. High levels of $16: 1 \omega 7 \mathrm{c}(24 \%)$ and $18: 1 \omega 7 \mathrm{c}(24 \%)$ were characteristic of this organism. Monoenoic fatty acids represented $62 \%(-$ VFA) and $60 \%$ (+VFA) of the total. Neither 10-methyl nor cyclopropyl FAME were detected.

Desulfovibrio thermophilus grown on pyruvate had no detectable unsaturated fatty acids. Oddnumbered and branched-chain fatty acids predominated (51 and $87 \%$ respectively) in this 
species, in contrast to the other organisms. The major fatty acids were iso16:0 and anteiso $17: 0$.

Desulfuromonas acetoxidans 11070 , a sulphur-reducing bacterium grown on acetate plus fumarate, exhibited a distribution of $91 \%$ even-numbered and $94 \%$ straight-chain fatty acids. This organism showed the highest proportions of the fatty acids $16: 0(47 \%)$ and $16: 1 \omega 7 \mathrm{c}(37 \%)$, which are common among all the strains examined except the Desulfovibrio thermophilus strain, which lacked $16: 1 \omega 7 \mathrm{c}$; otherwise, no distinctive components were detected.

The Campylobacter-like spirillum strain 5175, which also utilized elemental sulphur as an electron acceptor, was grown on fumarate. It had a distribution of predominantly evennumbered $(98 \%)$ and straight-chain $(99 \%)$ fatty acids. The major fatty acids were $16: 1 \omega 7 \mathrm{c}$ $(50 \%)$ and $16: 0(32 \%)$.

Fig. 1 shows a graphic representation of all the organisms examined based on the percentage unsaturation and percentage branching in their fatty acids. Organisms showing homology of morphological and physiological parameters (e.g. the Desulfobacter spp.) are grouped. The sulphur-reducing bacteria (Desulfuromonas and the spirillum) are encircled with broken lines to distinguish them from the sulphate-reducing bacteria. No other homology of characters in the sulphur reducers is implied.

\section{DISCUSSION}

All the strains examined could be differentiated by their respective distributions of phospholipid ester-linked fatty acids.

The Desulfobacter spp. exhibited homology of fatty acid biomarkers. High levels of cyclopropyl and 10Me16:0 fatty acids were observed with largely an even-numbered, straightchain fatty acid distribution after growth on acetate. This is in agreement with Taylor \& Parkes (1983), who examined the fatty acids of Desulfobacter sp. 3ac10. Our profile for 3 ac10 also included low levels of 10Me17:0 and 10Me18:0 (Table 2). These unusual fatty acids, as well as $10 \mathrm{Me} 15: 0$, were also found in other Desulfobacter spp. No other genera contained 10-methyl fatty acids. Kroppenstedt \& Kutzner (1978) showed that 10-methyl fatty acids occur in actinomycetes and increase as a function of age; however, unlike Desulfobacter spp., 10Me17:0 and 10Me18:0 tend to dominate in these filamentous bacteria.

Some bacterial fatty acid profiles vary in composition according to external stimuli (temperature, $\mathrm{pH}$, nitrogen source, salinity, etc.; Lechevalier, 1976). In order to use specific fatty acid biomarkers to interpret environmental community structure, micro-organisms should be examined for fatty acid patterns and their variation under different conditions. Taylor \& Parkes (1983) showed that fatty acid profiles in some sulphate-reducing bacteria can be influenced by carbon source; however, in all cases major fatty acid biomarkers were identifiable. With three separate cultures of Desulfobulbus sp. 3pr10 it was shown that growth on propionate produced an odd carbon number straight-chain profile, $\mathrm{CO}_{2} / \mathrm{H}_{2}$ produced an even carbon number straight-chain profile and lactate an approximately equal distribution of odd and even carbon number and of straight and branched chains. These changes could be explained in terms of the carbon sources being used as fatty acid chain initiators. This study is concerned with the induced variation in fatty acid profiles due to the presence of propionate and branchedchain volatile fatty acids. The latter are formed in sediments and sludges by fermentative breakdown of branched-chain amino acids. With the exception of isobutyrate being oxidized by Desulfotomaculum acetoxidans (Widdel \& Pfennig, 1981b), none of the added VFA could be utilized as electron donor by the sulphate reducers. The present study has shown that interpretation of environmental data using lipids should consider the potential effect of a variety of VFA produced by fermentative bacteria, which may change the fatty acid distributions of various micro-organisms present. Ingram et al. (1977) showed that exogenous propionate can be incorporated as a chain initiator into Escherichia coli fatty acids during growth on glucose broth, giving rise to odd-numbered chains. It seems likely that the VFA incorporated into strains 2ac9, $\mathrm{AcBa}$ and 5575 were used as chain initiators, because all three cultures displayed increased proportions of odd carbon number and branched fatty acids (see Tables 2 and 3). Desulfobacter sp. AcBa grown in media containing VFA synthesized anteiso14:0 and anteiso16:0; the 
presence of these fatty acids could not be interpreted in terms of any of the VFA being used as chain initiator (Kaneda, 1977).

Carbon sources influenced 10-methyl fatty acids and their straight-chain equivalents in similar ways; their proportion was lowered when odd-numbered and branched VFA were incorporated into the growth medium. As Kroppenstedt \& Kutzner (1978) suggest, this implies that $10 \mathrm{Me} 16: 0$ is formed by methylation at the 10th carbon after initial synthesis of a monounsaturated 16-carbon acid. If so, this almost certainly takes place in situ to the esterified phospholipid in the membrane (Akamatsu \& Law, 1970).

The 'fat vibrio' strain AcKo exhibits both nutritional and fatty acid profile similarities to Desulfobacter spp.; however, strain AcKo has no 10-methyl fatty acids.

Desulfotomaculum acetoxidans 5575 grown on acetate exhibited a very different fatty acid distribution compared with that of the Desulfobacter spp. or the 'fat vibrio' AcKo. Neither cyclopropyl nor 10-methyl fatty acids were detected. The predominant fatty acids were $16: 1 \omega 7 \mathrm{c}$, $18: 1 \omega 7 \mathrm{c}$ and 16:0. The presence of substantial amounts of unsaturated fatty acid in Desulfotomaculum acetoxidans $(62 \%)$, Desulfuromonas acetoxidans $(44 \%)$ and the Campylobacterlike spirillum (63\%), as compared to the other sulphide-forming bacteria, probably does not indicate a physiological or genealogical relationship. Nutritionally, these species are very different; moreover, the sporogenous Desulfotomaculum acetoxidans belongs to the Clostridium branch of the Gram-positive bacteria, whereas Desulfuromonas and the spirillum are Gramnegative (Fowler et al., 1985). Bacteria actually assigned to the genus Campylobacter exhibit high levels of unsaturation (approximately $50 \%$ ), with no branched fatty acids (Blaser et al., 1980), and have fatty acid profiles that are similar to that of the Campylobacter-like spirillum 5175 (although strain 5175 exhibited some branched fatty acids).

Desulfovibrio thermophilus, unlike other Desulfovibrio spp. (Edlund et al., 1985), exhibited no detectable unsaturated fatty acids; however, $87 \%$ were iso or anteiso branched. Silvius \& McElhaney $(1979 a, b)$ have shown that iso and anteiso branching provide the same effect as unsaturation with respect to membrane fluidity. This could explain why some bacteria have a low degree of fatty acid branching with high unsaturation and others have completely the reverse. Thus the Campylobacter-like spirillum and Desulfovibrio thermophilus may achieve the same effect by different mechanisms.

The ratios of unsaturation to branching of the fatty acids of different sulphide-forming bacteria can be used to distinguish certain physiological and taxonomic groups (Fig. 1). This does not apply to Desulfotomaculum acetoxidans and the sulphur-reducing spirillum, but the presence or absence of certain fatty acids (Table 3) can be used to separate these two organisms.

In this study we have shown that among the sulphide-forming bacteria examined only members of the genus Desulfobacter (all acetate utilizers) contain the fatty acid 10Me16:0. Other genera containing 10Me16:0 in their fatty acids include members of the actinomycetales (Kroppenstedt \& Kutzner, 1978). However, those members which do exhibit 10-methyl fatty acids have major quantities of $10 \mathrm{Me} 18: 0$, but not of $10 \mathrm{Me} 16: 0$. Preliminary attempts to assess the contribution of these actinomycetes to the microbial biomass of marine sediments appear to indicate that they are terrestrial organisms that have been washed into the sea, where they do not contribute to biomass turnover (Goodfellow \& Haynes, 1984). Thus the presence of 10Me16:0 and cy $17: 0$, without high levels of $10 \mathrm{Me} 18: 0$, seems to have the potential to act as a biomarker for Desulfobacter spp. in marine sulphate-reducing environments.

The authors would like to thank P. D. Nichols, A. T. Mikell, T. Phelps, C. A. Mancuso, and J. B. Guckert for discussions, H. Hippe for providing Desulfovibrio thermophilus, and R. Cord-Ruisch for isolation of Desulfobacter sp. AcBa. C. Antworth is particularly thanked for his help with the GC-MS data. Hewlett Packard is thanked for the generous donation of the GC-MS computer system. N.J.E.D. was supported by National Aeronautics and Space Administration grant number NAG 149 as part of the CELSS program.

\section{REFERENCES}

Akamatsu, Y. \& LAW, J. H. (1970). Enzymatic alkylation of phospholipid fatty acid chains by extracts of Mycobacterium phlei. Journal of Biological Chemistry 245, 701-708.
BANAT, I. M. \& Nedwell, D. B. (1983). Mechanism of turnover of $\mathrm{C}_{2}-\mathrm{C}_{3}$ fatty acids in high sulphate and low sulphate anaerobic sediments. FEMS Microbiology Letters 17, 107-110. 
Banat, I. M., Lindstrom, E. B., Nedwell, D. B. \& BALBA, M. T. (1981). Evidence for coexistence of two distinct functional groups of sulphate-reducing bacteria in salt marsh sediment. Applied and Environmental Microbiology 42, 985-992.

Blaser, M. J., Moss, C. W. \& Weaver, R. E. (1980). Cellular fatty acid composition of Campylobacter fetus. Journal of Clinical Microbiology 11, 448-451.

BLIGH, E. G. \& DYER, W. M. (1959). A rapid method of lipid extraction and purification. Canadian Journal of Biochemical Physiology 35, 911-917.

BobBIE, R. J. \& WhITE, D. C. (1980). Characterization of benthic microbial community structure by high resolution gas chromatography of fatty acid methyl esters. Applied and Environmental Microbiology 39, 1212-1222.

Boon, J. J., De Leeuw, J. W., Hoek, G. J. \& Vosjan, J. H. (1977). Significance and taxonomic value of iso and anteiso monoenoic fatty acids and branched beta-hydroxy acids in Desulfovibrio desulfuricans. Journal of Bacteriology 129, 1183-1191.

Brandis, A. \& Thauer, R. K. (1981). Growth of Desulfovibrio species on hydrogen and sulphate as sole energy source. Journal of General Microbiology 126, 249-252.

Campbell, I. M. \& Naworal, J. (1969). Mass spectral discrimination between monoenoic and cyclopropanoid, and between normal, iso, and anteiso fatty acid methyl esters. Journal of Lipid Research 10, 589592.

Dinh-Nguyen, N., Ryhage, R., Stallberg-StenHAGEN, S. \& StenhageN, E. (1961). Mass spectrometric studies. VIII. A study of normal long chain methyl esters and hydrocarbons under electron impact with the aid of deuterium-substituted compounds. Arkiv for Kemi 18, 393-399.

Dunkelblum, E., TaN, S. H. \& Silk, P. J. (1985). Double bond location in monounsaturated fatty acids by dimethyl disulphide derivatization and mass spectrometry: application to analysis of fatty acids in pheromone glands of four lepidoptera. Journal of Chemical Ecology 11, 265-277.

Edlund, A., Nichols, P. D., Roffey, R. \& White, D. C. (1985). Extractable and lipopolysaccharide fatty acid and hydroxy acid profiles from Desulfovibrio species. Journal of Lipid Research 26, 982-988.

Fowler, V. J., Widdel, F., Pfennig, N., Woese, C. R. \& Stackebrandt, E. (1985). Phylogenetic relationships of sulphate- and sulphur-eubacteria. Systematic and Applied Microbiology (in the Press).

GEHRON, M. J. \& WHITE, D. C. (1983). Sensitive assay of phospholipid glycerol in environmental samples. Journal of Microbiological Methods 1, 23-32.

Goodfellow, M. \& HAYNES, J. A. (1984). Actinomycetes in marine sediments. In Biological, Biochemical, and Biomedical Aspects of Actinomycetes, pp. 452472. Edited by L. Ortiz-Ortiz, L. F. Bojalil \& V. Yakoleff. New York: Academic Press.

Ingram, L. O., Chevalier, L. S., Gabbay, E. J., Ley, K. D. \& Winters, K. (1977). Propionate-induced synthesis of odd-chain length fatty acids by Escherichia coli. Journal of Bacteriology 131, 1023-1025.

INGVORSEN, K., ZEHNDER, A. J. B. \& JøRGENSEN, B. B. (1984). Kinetics of sulphate and acetate uptake by Desulfobacter postgatei. Applied and Environmental Microbiology 47, 403-408.
JøRGENSEN, B. B. (1977). The sulphur cycle of a coastal marine sediment (Limfjord, Denmark). Limnology and Oceanography 22, 814-832.

JøRGENSEN, B. B. (1982). Ecology of the bacteria of the sulphur cycle with special reference to anoxic/oxic interface environments. Philosophical Transactions of the Royal Society. Series B 298, 543-561.

KANEDA, T. (1977). Fatty acids of the genus Bacillus: an example of branched chain preference. Bacteriological Reviews 41, 391-418.

Kaneshiro, T. \& MarR, A. G. (1961). Cis-9,10methylene hexadecanoic acid from the phospholipids of Escherichia coli. Journal of Biological Chemistry 256, 2615-2619.

KIDWELl, D. A. \& Bleman, K. (1982). Determination of double bond position and geometry of olefins by mass spectroscopy of their Diels-Alder adducts. Analytical Chemistry 54, 2462-2465.

Kristjansson, J. K., Schönheit, P. \& Thauer, R. K. (1982). Different $K_{s}$ values for hydrogen of methanogenic bacteria and sulfate-reducing bacteria: an explanation for the apparent inhibition of methanogenesis by sulfate. Archives of Microbiology 131, 278282.

KROPPENSTEDT, R. M. \& KUTZNER, H. J. (1978). Biochemical taxonomy of some problem actinomycetes. Zentralblatt für Bakteriologie. Mikrobiologie und Hygiene (Abteilung I) supplement 6, 125-133.

LeCheVAlieR, M. P. (1976). Lipids in bacterial taxonomy-a taxonomist's view. CRC Critical Reviews in Microbiology 7, 109-210.

LOVELEY, D. R., DWYER, D. F. \& KLUG, M. J. (1982). Kinetic analysis of competition between sulfate reducers and methanogens for hydrogen in sediment. Applied and Environmental Microbiology 43, 13731379.

McCloskey, J. A. \& LAw, J. H. (1967). Ring location in cyclopropane fatty acid esters by a mass spectrometric method. Lipids 2, 225-230.

Makula, R. A. \& FINNERTY, W. R. (1974). Phospholipid composition of Desulfovibrio species. Journal of Bacteriology 120, 523-529.

MAKUla, R. A. \& FinNERTY, W. R. (1975). Isolation and characterization of an ornithine-containing lipid from Desulfovibrio gigas. Journal of Bacteriology 120, 1279-1283.

Minnikin, D. E., Goodfellow, M. \& Collins, M. D. (1978). Lipid composition in the classification and identification of Coryneforms and related taxa. In Coryneform Bacteria, pp. 85-160. Edited by 1. J. Bousfield \& A. G. Calley, London: Academic Press.

Nichols, P. D., Shaw, P. M. \& Johns, R. B. (1985). Determination of monoenoic double bond position and geometry in complex microbial environmental samples by capillary GC-MS of their Diels-Alder adducts. Journal of Microbiological Methods 3, 311319.

PARKes, R. J. \& TAYLOR, J. (1983). The relationship between fatty acid distributions and bacterial respiratory types in contemporary marine sediments. Estuarine, Coastal and Shelf Science 16, 173-189.

Perry, G. J., Volkman, J. K. \& Johns, R. B. (1979). Fatty acids of bacterial origin in contemporary marine sediments. Geochimica et cosmochimica acta 43, 1715-1725. 
Pfennig, N. \& BIEBl, H. (1976). Desulfuromonas acetoxidans gen. nov. and sp. nov., a new anaerobic, sulphur reducing, acetate-oxidising bacterium. Archives of Microbiology 110, 3-12.

PfenNig, N. \& Biebl, H. (1981). The dissimilatory sulfur-reducing bacteria. In The Prokaryotes, vol. 1, pp. 941-947. Edited by M. P. Starr, H. Stolp, H. G. Truper, A. Balows \& H. G. Schlegel. Berlin \& New York: Springer-Verlag.

PfenNig, N., Widdel, F.\& Truper, H. G. (1981). The dissimilatory sulfate-reducing bacteria. In The Prokaryotes, vol. 1, pp. 926-940. Edited by M. P. Starr, H. Stolp, H. G. Truper, A. Balows \& H. G. Schlegel. Berlin \& New York: Springer-Verlag.

PostGate, J. R. (1984). The Sulphate-reducing Bacteria, 2nd edn. Cambridge: Cambridge University Press.

Rohwedder, W. D., Mabrouk, A. F. \& Selke, E. (1965). Mass spectrometric studies of unsaturated methyl esters. Journal of Physical Chemistry 69, 17111715 .

Rozanova, E. P. \& Khudyakova, A. I. (1974). A new non-spore-forming thermophilic sulfate-reducing organism, Desulfovibrio thermophilus nov. spec. Microbiology 43, 908-912.

RYhaGe, R. \& StENhagen, E. (1958). Mass spectrometric studies. I. Methyl esters of saturated normal chain carboxylic acids. Archiv för Kemi 13, 523-534.

SANSONE, F. J. \& MARTENS, C. S. (1982). Volatile fatty acid cycling in organic rich marine sediments. Geochimica et cosmochimica acta 46, 1575-1589.

Schönheit, P., KRistjansson, J. K. \& ThaueR, R. K. (1982). Kinetic mechanism for the ability of sulfate reducers to out-compete methanogens for acetate. Archives of Microbiology 132, 285-288.

Silvius, J. R. \& McElhaney, R. N. (1979a). Effects of phospholipid acyl chain structure on physical properties. I. Isobranched phosphatidylcholines. Chemistry and Physics of Lipids 24, 287-296.

Silvius, J. R. \& McElhaney, R. N. (1979b). The effects of phospholipid acyl chain structure on the thermotropic phase properties. 2. Phosphatidylcholines with unsaturated or cyclopropane acyl chains. Chemistry and Physics of Lipids 25, 125-134.

SMITH, R. L. \& KLUG, M. J. (1981). Reduction of sulfur compounds in the sediments of a eutrophic lake basin. Applied and Environmental Microbiology 41, 1230-1237.

Sørensen, J., Christensen, D. \& Jørgensen, B. B. (1981). Volatile fatty acids and hydrogen as substrates for sulphate-reducing bacteria in anaerobic marine sediment. Applied and Environmental Microbiology 42, 5-11.
Stieb, M. \& SchinK, B. (1985). Anaerobic oxidation of fatty acids by Clostridium bryantii sp. nov., a sporeforming, obligately syntrophic bacterium. Archives of Microbiology 140, 387-398.

TAYLOR, J. \& PARKES, R. J. (1983). The cellular fatty acids of the sulphate-reducing bacteria, Desulfobacter sp., Desulfobulbus sp. and Desulfovibrio desulfuricans. Journal of General Microbiology 129, 3303-3309.

TAYLOR, J. \& PARKES, R. J. (1985). Identifying different populations of sulphate-reducing bacteria within marine sediment systems, using fatty acid biomarkers. Journal of General Microbiology 131, 631-642.

UEKI, A. \& SUTO, T. (1979). Cellular fatty acid composition of sulphate-reducing bacteria. Journal of General and Applied Microbiology 25, 185-196.

Volkman, J. K., Johns, R. B., Gillan, F. T., Perry, G. J. \& BAVOR, H. J. (1980). Microbial lipids of an intertidal sediment. I. Fatty acids and hydrocarbons. Geochimica et cosmochimica acta 44, 1133-1143.

WHITE, D. C. (1983). Analysis of microorganisms in terms of quantity and activity in natural environments. Symposia of the Society for General Microbiology 34, 37-66.

White, D. C., Davis, W. M., Nickels, J. S., King, J. D. \& BobBIE, R. J. (1979). Determination of the sedimentary microbial biomass by extractible lipid phosphate. Oceologia 40, 51-62.

WIDDEL, F. \& PfENNIG, N. (1977). A new anaerobic, sporing, acetate-oxidising sulphate-reducing bacterium Desulfotomaculum (emend) acetoxidans. Archives of Microbiology 112, 119-122.

Widdel, F. \& PFennig, N. (1981a). Studies on dissimilatory sulphate-reducing bacteria that decompose fatty acids. I. Isolation of new sulphatereducing bacteria enriched with acetate from saline environments. Description of Desulfobacter postgatei gen. nov., sp. nov. Archives of Microbiology 129, 395400.

Widdel, F. \& PfenNig, N. (1981 $b$ ). Sporulation and further nutritional characteristics of Desulfotomaculum acetoxidans. Archives of Microbiology 129, 401-402.

Winfrey, M. R. \& Zeikus, J. G. (1977). Effect of sulfate on carbon and electron flow during microbial methanogenesis in freshwater sediments. Applied and Environmental Microbiology 33, 275-281.

Wolfe, R. S. \& Pfennig, N. (1977). Reduction of sulphur by Spirillum 5175 and syntrophism with Chlorobium. Applied and Environmental Microbiology 33, 427-433. 